\title{
OCORRÊNCIA DE GRANULITOS EMPOBRECIDOS NAS PORÇÕES BASAIS DA NAPPE DE EMPURRÃO SOCORRO-GÜAXUPE
}

\author{
M.C.Campos Neto ${ }^{1}$, V.A.Janasi ${ }^{1}$, R.Caby ${ }^{2}$
}

Na Nappe de Empurrão Socorro-Guaxupé (NESG) as rochas granulíticas s.l. ocorrem com freqüência, especialmente em suas porções basais, expostas nos extremos $\mathrm{N}$ e E do segmento setentrional da estrutura e no extremo $\mathrm{N}$ do segmento meridional. Em áreas estudadas com maior detalhe, tem sido demonstrado que elas incluem tipos petrográficos bastante diversos, tais como granada granulitos, charnockitos cálcio-alcalinos potássicos e mangeritos.

Charnockitos cálcio-alcalinos potássicos foram inicialmente reconhecidos na borda do Complexo Socorro por Wernick et al. (1984) e formam diversos corpos ainda não mapeados, principalmente como os da região de Muzambinho-Guaxupé, no segmento setentrional da NESG e como as ocorrências nas imediações de Paraisópolis, segmento meridional. Os charnockitos de Muzambinho foram datados em ca. 660 (U-Pb em zircão e isócrona Rb-Sr; Basei et al., 1995), valor este que se situa dentro do episódio admitido para o magmatismo de arco no sistema orogênico neoproterozóico que inclui a NESG e a Faixa Apiaí (Figueiredo \& Campos Neto, 1984).

Os mangeritos ocorrem principalmente ao longo de uma faixa, com extensão de cerca de $100 \mathrm{~km}$, na porção central do segmento setentrional da NESG. São corpos tabulares e intrusivos, afetados por zonas de cisalhamento dúctil com transporte da placa superior para noroeste e dobrados. Compõem-se de associações mangerito-graníticas (Suite São José do Rio Pardo, SJRP, de Campos Neto et al., 1988), derivadas do fracionamento in situ de magmas quartzo mangeríticos (Janasi, 1996). Os mangeritos normalmente podem ser distinguidos, no campo, dos charnockitos cálcio-alcalinos, pela ausência seja de texturas porfiríticas seja da biotita como máfico comum, características freqüentes dos charnockitos. Em termos geoquímicos os mangeritos constituem um grupo bastante peculiar, especialmente por apresentarem teores de $\mathrm{Ca}, \mathrm{Sr}$ e Mg\# mais baixos e alto $\mathrm{Zr}$ (Campos Neto et al., 1988), indicativos de origem por fusão de crosta granulítica empobrecida a T superiores a $950^{\circ} \mathrm{C}$ (Janasi, 1996). Idades U-Pb em zircão indicam sua geração há ca. 630-625 Ma (Basei et al., 1995).

Em contraposição aos dois grupos acima descritos, de caráter nitidamente plutônico, ocorrem na base da NESG, tanto no segmento setentrional quanto no meridional, granulitos s.s., de caráter bandado, com alternância de niveis métricos a decimétricos de composição máfica e intermediária. Estimativas termobarométricas em granulitos básicos indicam que a sua cristalização ocorreu a ca. $8,5 \mathrm{kbar}$ e $850^{\circ} \mathrm{C}$ (Iyer et al., 1996); condições ainda mais extremas $\left(\mathrm{P} \geq 11 \mathrm{kbar}\right.$ e $\left.\mathrm{T}=\mathrm{ca} .950^{\circ} \mathrm{C}\right)$ foram estimadas por Vasconcellos et al. (1991) em granada granulitos de composição intermediária que afloram na região de Varginha, na lâmina inferior da NESG. Embora potencialmente correspondendo a áreas-fonte do plutonismo anidro representado pelos dois conjuntos anteriores, esses granulitos são ainda muito pouco

\footnotetext{
${ }^{1}$ DGG, Instituto de Geociências, Universidade de São Paulo.

${ }^{2}$ Laboratoire de Tectonophiysique, Université de Montpellier II, France.
} 
conhecidos do ponto de vista geoquímico. De fato, os trabalhos prévios que procuraram reconhecer padrões geoquímicos gerais para os "granulitos" da NESG (Fernandes et al., 1987; Iyer et al., 1995), não separam especificamente estas rochas do plutonismo que se seguiu. Como resultado, identificou-se uma grande dispersão composicional, apesar de, na média, um caráter levemente empobrecido seja ressaltado pelos valores elevados da razão $\mathrm{K} / \mathrm{Rb}$ e teores muito baixos de Th (da ordem de $2 \mathrm{ppm})$.

Com o objetivo de melhor caracterizar especificamente os granulitos basais da NESG, foram estudadas, petrográfica e geoquimicamente, amostras provenientes de três ocorrências, situadas nas regiões de Varginha e Guaxupé (segmento setentrional) e Piranguinho (segmento meridional). Trata-se, em todos os casos, de granada granulitos bandados, de granulação média, em parte com leucossomas estromáticos anidros mais grossos. Composicionalmente, as bandas claras correspondem a enderbitos ou, mais raramente, charnockitos hololeucocráticos, as bandas escuras são usualmente gabronoríticas.

Em termos químicos, trata-se de um conjunto heterogêneo, dominado por rochas metaluminosas de caráter cálcio-alcalino relativamente pobres em $\mathrm{K}$ (em média, ca. $2 \%$ $\mathrm{K}_{2} \mathrm{O} ; \mathrm{K}_{2} \mathrm{O} / \mathrm{Na}_{2} \mathrm{O} \ll 1$ ), com mg\# variando de 0.56 nos termos máficos a 0.32 nos ácidos. Distinguem-se do conjunto principal uma amostra de rocha máfica cumulática da região de Guaxupé e outra de caráter tolético (maior Ti, P; mg\# $=0.24$ ) da região de Varginha. Um mangerito granatífero e homogêneo da região de Varginha é quimicamente similar aos mangeritos da suite SJRP $(\mathrm{mg \#}=25 ; \mathrm{Zr}=\mathrm{ca} .1300 \mathrm{ppm})$.

Dados preliminares de elementos incompativeis indicam a predominância de granulitos com teores sensivelmente baixos de $\mathrm{Rb}(<80 \mathrm{ppm}$ em rochas intermediárias), Th e U (<1 ppm); por outro lado, em rochas mais ricas em K (ca. $\left.3 \% \mathrm{~K}_{2} \mathrm{O}\right)$, da região de Guaxupé, os teores de Th alcançam valores elevados, da ordem de $10-20 \mathrm{ppm}$.

A análise dos dados geoquímicos, ora obtidos e dos disponiveis na literatura, mostra que essa associação basal da NESG, embora heterogênea, forma um grupo quimicamente distinto dos charnockitos e mangeritos plutônicos, precisando assim ser deles distinguidos nas investigações sobre o caráter granulítico desse terreno. As principais diferenças observadas ressaltam os teores mais baixos de elementos fortemente incompativeis, especialmente $\mathrm{K}, \mathrm{Rb}$ e Th e sugerem que esses granulitos poderiam, em parte, corresponder a rochas residuais derivadas de eventos de fusão parcial de crosta inferior. Essas rochas podem ter contribuído para ambos os eventos plutônicos, especialmente o mangerítico, de fonte essencialmente crustal. Representantes desses magmas ainda podem ocorrer difusamente junto a esses granulitos, como no caso do granada mangerito acima descrito.

Os granulitos são de idade ainda desconhecida, mas, se produtos residuais de processos de fusão parcial no auge metamórfico, sob condições de temperatura na ordem de $950^{\circ} \mathrm{C}$, podem incluir contribuições básicas neoproterozóicas, que testemunhariam material subcrustal acrescido, em parte responsável pela extrema anomalia térmica observada.

\section{Referências Bibliográficas}

BASEI, M.A.S.; SIGA JR., O.; SATO, K.; SPROESSER, W.M. (1995) A metodologia urânio-chumbo na Universidade de São Paulo: princípios metodológicos, aplicações e resultados obtidos. Anais da Academia Brasileira de Ciências, v.67, n.2, p.221-237.

CAMPOS NETO, M.C.; FIGUEIREDO, M.C.H.; JANASI, V.A.; BASEI, M.A.S.; FRYER, B. (1988) The São José do Rio Pardo mangeritic-granitic suite, southeastern Brazil. Geochimica Brasiliensis, v.2, n.2, p.185-200.

FERNANDES, J.F.; IYER, S.S.; IMAKUMA, K.; CHOUDHURI, A. (1987) Geochemical studies in the Proterozoic metamorphic terrain of the Guaxupé Massif, Minas Gerais, 
Brazil. A discussion on large ion lithophile element fractionation during high-grade metamorphism. Precambrian Research, v.36, p.65-79.

FIGUEIREDO, M.C.H.; CAMPOS NETO, M.C. (1994) 0 arco magmático cálcio-alcalino de alto-K da microplaca Apiai-Guaxupé. In: CONGRESSO BRASILEIRO DE GEOLOGIA, 38., Camboriú, 1994. Anais. Camboriú, SBG, v.1, p.620-621.

IYER, S.S.; CHOUDHURI, A.; PATTISON, D.R.M.; DE PAOLI, G.R. (1996) Petrology and geochemistry of the Neoproterozoic Guaxupé granulite facies terrain, southeastern Brazil. Precambrian Research, v.77, p.23-40.

JANASI, V.A. (no prelo) Neoproterozoic mangerite-granite magmatism in southeastern Brazil: The São Pedro de Caldas massif. Anais da Academia Brasileira de Ciências.

VASCONCELLOS, A.C.B.; HARRIS, N.B.W.; TINDLE, A.G. (1991) The relationship between metamorphism and tectonics: evidence from the Socorro-Guaxupé Thrust Nappe, southeastern Brazil. In: TUISKU, P.; LAAJAKI, K. (Eds.) Metamorphism, deformation and structure of the crust. Oulu, The University of Oulu, p.86. (Res. Terras. Ser. A, 5).

WERNICK, E.; DIDIER, J.; ARTUR, A.C.; HORMANN, P. (1984) Caracterização da zona marginal charnockítica do Complexo Socorro nos arredores da cidade homônima, SP/MG. In: CONGRESSO BRASILEIRO DE GEOLOGIA, 33., Rio de Janeiro, 1984. Anais. Rio de Janeiro, SBG, v.6, p.2919-2934. 